\title{
Status of ClaRaCCS: Modelling and Simulation of Coal-Fired Power Plants with $\mathrm{CO}_{2}$ Capture
}

\author{
Johannes Brunnemann ${ }^{* 1}$, Friedrich Gottelt ${ }^{1}$, Kai Wellner ${ }^{2}$, Ala Renz ${ }^{1}$, André Thüring ${ }^{4}$, Volker \\ Roeder $^{3}$, Christoph Hasenbein ${ }^{3}$, Christian Schulze ${ }^{4}$, Gerhard Schmitz ${ }^{2}$ and Jörg Eiden ${ }^{1}$ \\ ${ }^{1}$ XRG Simulation GmbH, Harburger Schlossstraße 6-12, 21079 Hamburg, Germany \\ ${ }^{2}$ University Hamburg-Harburg, Inst. of Thermo-Fluid Dynamics, Denickestr. 17, 21073 Hamburg, Germany \\ ${ }^{3}$ University Hamburg-Harburg, Inst. of Energy Systems, Denickestr. 15, 21073 Hamburg, Germany \\ ${ }^{4}$ TLK-Thermo GmbH, Hans-Sommer-Str. 5, 38106 Braunschweig, Germany
}

\begin{abstract}
Within the DYNCAP project, the Modelica library ClaRaCCS is being developed. This library will provide a framework to model both steam power plants and carbon capture units in an integrated manner. The current status of the library is presented. The structure of the library and the general model design is outlined. Its user-friendly handling as well as its high flexibility in the modelling of individual complex scenarios are demonstrated by the concrete modelling of a furnace. The scenario of a closed steam cycle coupled to a carbon capture cycle based on an amine gas treatment is described and simulation results are briefly discussed.

Keywords: power plant; Clausius-Rankine cycle; $\mathrm{CO}_{2}$ capture; CCS; amine gas treatment; transient simulation; library
\end{abstract}

\section{Introduction}

The ongoing climate change is a serious ecological and economical challenge in the next decades. The Intergovernmental Panel on Climate Change (IPCC) recommends a reduction of $\mathrm{CO}_{2}$ emissions to below $80 \%$ until 2050 compared to 1990 [1]. Although the proportion of renewable energies is growing significantly, fossil fuels such as coal will remain central to the world's energy supply during the next decades.

It is therefore necessary to evaluate power plant technologies appropriate for a significant reduction of $\mathrm{CO}_{2}$ emissions in the short term. One already available technological solution is the capture of $\mathrm{CO}_{2}$ from flue gases of fossil-fuelled power plants and its storage (CCS). This technology has to be embedded into

*brunnemann@xrg-simulation.de a future energy mix with a large percentage of renewable and fluctuating energies, such as wind and solar power. Hence, the need for a flexible operation of conventional fossil-fuelled power plants under rapid, large and frequent load changes arises.

The evaluation of such variable operation scenarios requires a thorough investigation of future power plant dynamics. This shall result in recommendations for the design and operation of power plants, that meet certain objectives regarding efficiency, technical limitations and ecological standards. A valuable tool to tackle this challenging task is computer simulation.

As a part of COORETEC [2], an initiative of the German Federal Ministry of Economics and Technology, the project DYNCAP [3] aims at studying the dynamic behaviour of steam-power processes with $\mathrm{CO}_{2}$ capture in order to provide balancing energy. The project started in March 2011 and will be finished in September 2014. One major outcome of the project is the Modelica library ClaRaCCS (Clausius-Rankine with $\mathrm{CO}_{2}$ Capture and Storage). The goal of the library is to provide models for the analysis of complex power plants with $\mathrm{CO}_{2}$ capture in both static and dynamic operation mode. After completion of the DYNCAP project, the library will be freely available under the Modelica license. The current development is performed using Dymola [4], however the final version of the library is intended to work with SimulationX [5] as well.

This paper gives an introduction to ClaRaCCS and presents the current status of development. The paper is organised as follows: Section 2 summarises the technical fundamentals for conventional steam power plants as well as carbon capture processes modelled in the library. In Section 3 general properties of the li- 
brary are introduced: Starting from the general library structure the guiding principles, that underlie the models in ClaRaCCS, are explained. The treatment of media data as well as validation of models will also be outlined. The described properties will then be illustrated by a concrete modelling example in section 4 . where the model of a furnace is described. Section 5 demonstrates the current status of $\mathrm{ClaRaCCS}$ by giving an example of use: the model of a coal-fired power plant with attached carbon capture unit is presented. The results of a simulation scenario are shown, where throttling of the carbon capture unit is used in order to meet the demand for a short term increase of the generator power output of the plant. Finally, section 6 gives a summary and outlines future steps of development.

\section{Technical Background}

The processes covered in ClaRaCCS are conventional hard-coal-fired power plants and their derivatives for $\mathrm{CO}_{2}$ capture, the Post-Combustion Capture process (PCC) and the Oxyfuel process (further information in [6]). Lignite-fired power plants and gas-fired combined cycle power plants are not part of the project DYNCAP, but may be included in the future.

Because the model implementation of the Oxyfuel process is still work in progress the respective section will only give a short overview. The section of the PCC process will introduce a little more of this technology because it is part of the simulation example given in section 5 .

\subsection{Conventional Hard-Coal-Fired Power Plants}

State-of-the-art conventional hard-coal-fired power plants burn pulverised coal in the steam generator with air. The heat is transferred to a steam cycle that converts it to electric energy. The general simplified process scheme of the power plant is shown in figure 1. Mills pulverise and dry the raw hard-coal. The raw flue gas contains, additionally to nitrogen, $\mathrm{CO}_{2}$, oxygen and water, also certain amounts of nitrogen oxides, fly ash (dust) and sulphur oxides. Therefore the flue gas treatment comprises a denitrification system, an electrostatic precipitator and a wet desulphurisation unit.

The steam cycle comprises a super-heater and a reheater. Power plants currently under construction have a live steam (high pressure) pressure of about 285 bar and a live steam temperature of about $600^{\circ} \mathrm{C}$. The

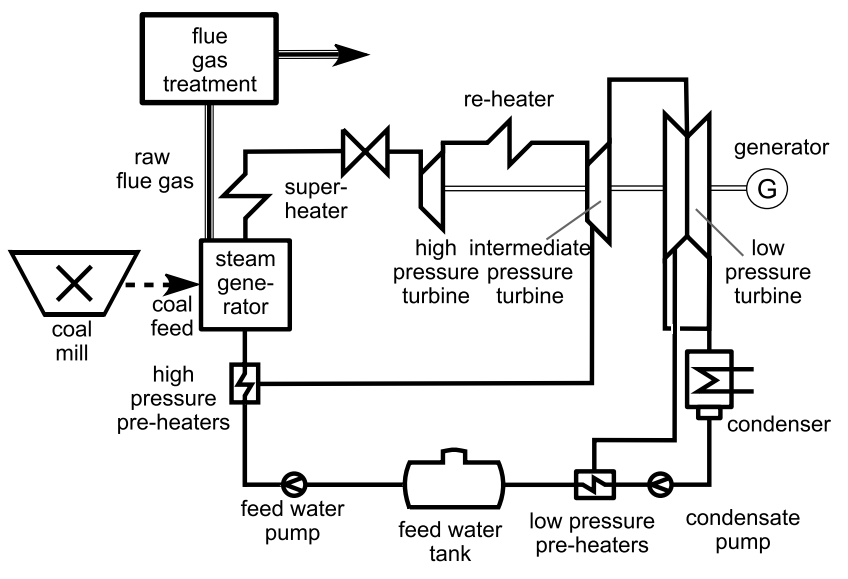

Figure 1: Simplified process scheme of a conventional power plant.

re-heated steam is in the range of $60 \mathrm{bar}$ and $620^{\circ} \mathrm{C}$. Feed water is pre-heated with steam in the low pressure range and the high pressure range. Up to nine feed water pre-heaters are implemented, each with a steam tapping from the turbines or crossover sections. The turbines are all coupled with the same shaft and running at constant speed in normal operation as they are directly coupled with the electric net by the generator.

The overall efficiency of such a power plant is approx. $46 \%$.

\subsection{Post-Combustion Capture Process}

In a $\mathrm{PCC} \mathrm{CO}_{2}$ is separated from the flue gas of a conventional coal-fired steam power plant by a chemical absorption-desorption process. The reduction of the $\mathrm{CO}_{2}$ emissions is accompanied by a significant loss in the electrical power output and a related net efficiency penalty of 8-12\%-pts. As reference the solvent Monoethanolamine (MEA) is used with a solvent mass fraction of $30 \% \mathrm{MEA}$ and a targeted $\mathrm{CO}_{2}$ capture rate of $90 \%$.

Figure 2 shows the schematic PCC process. The flue gas of the boiler passes through the flue gas treatment, where it is cleaned, and then enters the absorber column at the bottom, in which the $\mathrm{CO}_{2}$ is absorbed by a counter current solution flow. The treated gas is released to the atmosphere, while the rich $\left(\mathrm{CO}_{2}\right.$ loaded) solution leaves the absorber at the bottom. Downstream the absorber, the rich solution is pumped through the rich-lean heat exchanger, heated up and enters the desorber column at the top. In the desorber the absorbed $\mathrm{CO}_{2}$ is stripped from the rich solution. The required heat duty is provided by a reboiler in which steam from the power plant is condensed. From 
the bottom of the desorber, the lean solution is pumped to the entrance of the absorber, passing the rich-lean heat exchanger where it is cooled and pre-heats the rich solution. The captured $\mathrm{CO}_{2}$, nearly pure, is compressed and pumped to the storage. A detailed explanation of the process can be found in [7]. An overview of this process is given in [8].

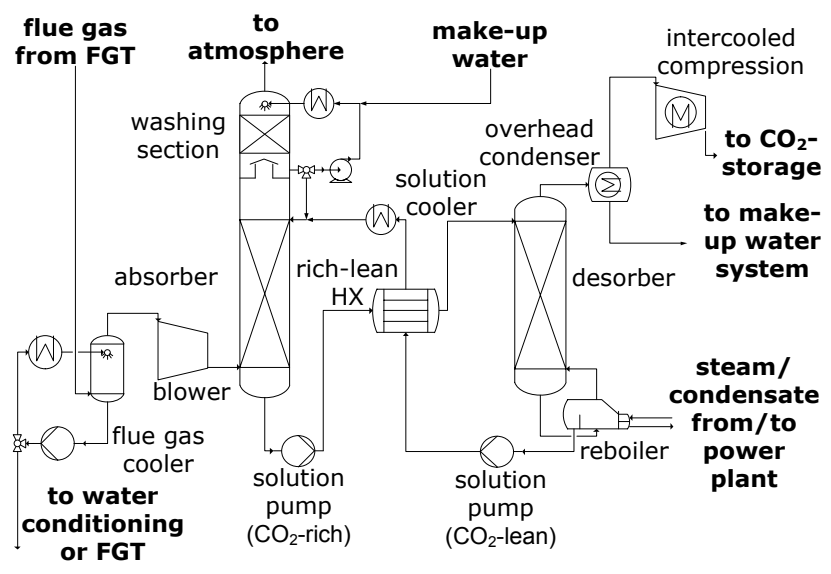

Figure 2: Flow sheet of the PCC process, cf. [7].

The main task of the PCC is the reduction of the $\mathrm{CO}_{2}$-emissions by a certain value. The $\mathrm{CO}_{2}$ capture rate depends on the circulated solution flow rate and the working capacity of the solution. Here the working capacity is defined as the difference between $\mathrm{CO}_{2}$ loadings behind the absorber and behind the desorber. The solution rate can be influenced by the pump upstream the absorber. The lean loading depends on the reboiler heat duty and thus is directly affected by the steam mass flow which is condensed in the reboiler. The liquid level of the absorber sump is controlled by a pump that conveys the solution to the desorber.

\subsection{Oxyfuel Process}

Conventional coal-fired power plants and power plants with PCC burn the coal with air. On the contrary, in the Oxyfuel process the coal is burnt in an atmosphere of oxygen from an air separation unit mixed with recirculated flue gas. As the nitrogen of the air is avoided in the combustion process, the flue gas contains mainly $\mathrm{CO}_{2}$ (70 vol.-\%), water and small amounts of oxygen, nitrogen and argon. The flue gas fraction that is not recirculated is treated to remove the impurities in order to receive a $\mathrm{CO}_{2}$ stream with a purity higher than $96 \%$. The overall power plant net efficiency is decreased by approx. 8-10\%-points when the Oxyfuel process is applied. This includes the cryogenic air separation unit and the compression of the captured $\mathrm{CO}_{2}$ to a pressure of 110 bar. A detailed overview of the Oxyfuel process can be found in [9].

\section{The ClaRaCCS Library}

\subsection{Library Structure}

Creating a library covering a very broad range of physics that is at the same time well-arranged and userfriendly, demands an elaborate library structure. Figure 3 shows the top level content of the ClaRaCCS library. Beside the usual packages like UsersGuide, Examples and Media the library is structured into the main existing functional groups of the physical processes under consideration. Components is the package with the most basic models describing e.g. turbo machines, furnace, heat exchangers or thermal separation. In SubSystems these components are used to create more complex models e.g. a boiler or an air separation unit. The package SubProcesses then in turn contains models which are built from SubSystems models like whole $\mathrm{CO}_{2}$ capture cycles. PowerPlants consists of models representing whole power plants and is the package with the most complex models.
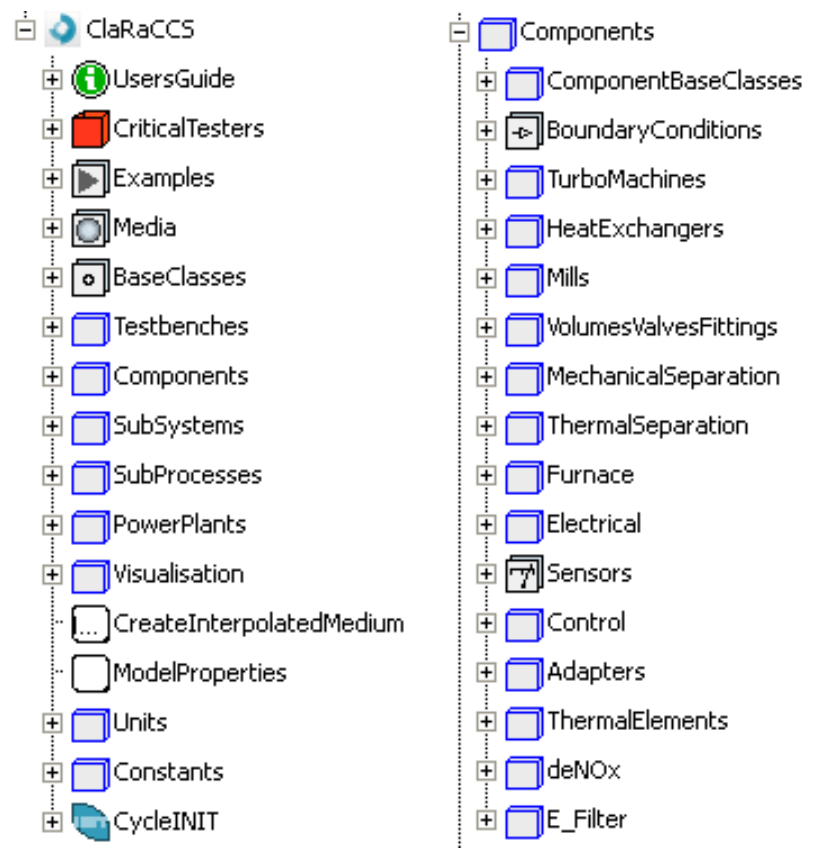

Figure 3: Top level content of the ClaRaCCS library and the central component package.

\subsection{Model Design Principles}

When setting up the model of a complex physical system such as a power plant, the first question to be answered is what physical fidelity is needed to cope with 
the given simulation task. The answer to this question refers to the level of detail necessary for each component and sub-process. The next step is to define the general physical effects to be considered for solving the given task. Finally, the level of physical insight into the considered physical aspects must be chosen.

In what follows it will be explained how these three stages guide the model design of the ClaRaCCS library. For illustration the concept will be applied to the wellknown example of a fluid flow in a pipe.

\subsubsection{Level of Detail}

In [10] a classification of component models into different levels of detail was developed. It is mainly based on two criteria:

- Purpose of model. In which simulation context will the model be used? What questions and physical effects shall be analysed with the model?

- Applicability of model. What are the main assumptions the model is based on? Are there some structural limitations?

The model design of ClaRaCCS has been inspired by these ideas. Moreover it aims to provide a well balanced combination of readability 1 modelling flexibility and avoidance of code duplication. Consequently, each component in the ClaRaCCS library is represented by a family of freely exchangeable models. Every component family is grouped into four levels of detail:

L1. Models are based on characteristic lines and / or transfer functions. This results in an idealised model, which shows physical behaviour. The model definition may be derived either from analytic solutions to the underlying physics or from phenomenological considerations. Applicability is limited to the validity of the simplification process. Non-physical behaviour may occur otherwise.

Example: transmission line model for fluid flow in a pipe.

L2. Models are based on balance equations. These equations are spatially averaged over the component. The models show a correct physical behaviour unless the assumptions for the averaging process are violated.

\footnotetext{
${ }^{1}$ This results in a flat model hierarchy and restricts the use of inheritance.
}

Example: single control volume for fluid flow in a pipe.

L3. Models are by construction subdivided into a fixed number of spatial zones. The spatial localisation of these zones is not necessarily fixed and can vary dynamically. For each zone a set of balance equations is used and the model properties (e.g. media data) are averaged zone-wise. The models show a correct physical behaviour unless the assumptions for the zonal subdivision and the averaging process over zones are violated.

Example: moving boundary approach for fluid flow in a pipe.

L4. Models can be subdivided into an arbitrary number of spatial zones (control volumes) by the user. They thus provide a true spatial resolution. For each zone a set of balance equations is used which is averaged over that zone. The model shows a correct physical behaviour unless the assumptions for the choice of grid and the averaging process over the control volumes are violated. Example: finite volume approach with spatial discretisation in flow direction for fluid flow in a pipe.

\subsubsection{Physical Effects to be Considered}

Once the decision for a specific detail group of models is made, the set of required physical effects to be covered by a model may still differ according to the simulation goal. For instance, in a pipe model it might be necessary to resolve the spatial flow properties but unnecessary to analyse sound waves in detail. This is reflected in the complexity of the basic physical equations underlying the model.

Notice that, although the ClaRaCCS library is designed for dynamic simulations, it is still possible to include models, where parts of the basic physical equations correspond to the stationary behaviour of a component. Such models are often favourable with respect to computation time and stability. Their use is appropriate whenever certain aspects of the component dynamics can be neglected compared to the system dynamics under consideration. In the pipe example above this would be manifested by the fact that if only fluid flow properties (temperature profile, flow velocities, etc.) are of interest, sound wave propagation can be neglected, as long as the flow velocity is much less than the speed of sound. Consequently a stationary momentum balance for the fluid would be sufficient in this case. 
In order to cope with these different needs, the ClaRaCCS library provides component models at the same level of detail but covering different physical effects. They are distinguished by different self explaining names.

\subsubsection{Level of Insight}

By now, the fundamental equations of a model are defined by setting its level of detail and the physical effects of consideration. However, these equations declare which physical effects are considered, but not how they are considered. For instance, the pressure loss in a pipe may be modelled using constant nominal values or via correlations taking the flow regime and the fluid states into account. These physical effects are therefore modelled in replaceable models that complete the fundamental equations using predefined interfaces, e.g. the friction term in the momentum balance. By separating the governing model definition from the underlying sub-models, the flexibility of the model is enhanced without loosing readability.

\subsection{Media Data}

The property data for all models will be provided by medium classes which then in turn call external Cfunctions. However, up to now only the models of the conventional part of the plant obtain their property data from external functions. The observed advantage of this procedure is the possible access to other commercial external fluid property libraries and a large increase in simulation speed of the models. The implementation of external property data for the multicomponent media used in the PCC is still work in progress. The current state of this issue and the experiences with external, table-based media data for singlecomponent media are very encouraging concerning simulation speed and simulation stability.

For the sake of initialisation and numerical stability the choice of different state variables may be of high importance. Depending on the selection of the respective state variables an index reduction can be necessary. Also phase and reaction equilibria can lead to high index systems which have to be reduced symbolically. In both cases it is likely that derivatives of property data are required to perform index reduction. Providing these derivatives still is a challenge to be overcome during this project.

\subsection{Model Validation}

Models in the ClaRaCCS library will be validated against established process modelling and power plant software (Aspen Plus and Ebsilon [11, 12]) as well as dynamic measurement data.

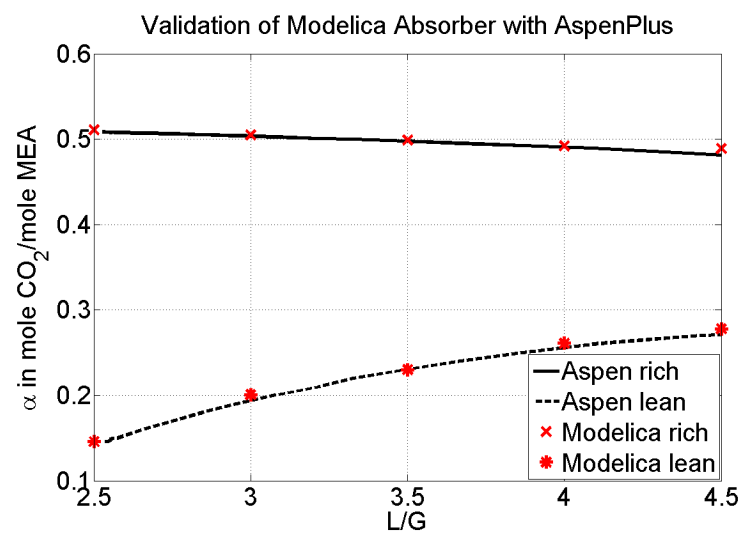

Figure 4: Validation example. Modelica absorber vs. [11]. Lean and rich solution. Here $\alpha$ denotes the amount of substance $\mathrm{CO}_{2}$ per amount of substance solvent (MEA). $L$ denotes the mass flow rate of the solvent and $G$ is the flue gas mass flow rate.

For the water steam cycle this measurement data are provided by the coal fired power plant [13] at Rostock, Germany, with a net power output of $500 \mathrm{MW}$. For the PCC process the data are provided by a pilot plant [14] at Heilbronn, Germany, which has the capacity to clean approximately $1150 \mathrm{Nm}^{3} / \mathrm{h}$ of flue gas.

\section{Modelling of Furnace}

The purpose of this section is the illustration of the general modelling strategy as introduced in section 3 As an example the furnace model package that provides models for burner, flame rooms and hoppers with different levels of detail is considered. Here, predominantly the structure of the package is described without covering the physics inside in more detail.

\subsection{Connectors}

Although parts of ClaRaCCS and Modelica.Fluid cover similar fields of application own connectors for liquids, fluids and gas mixtures are necessary due to the usage of external media as motivated in 3.3 . However, models of the Modelica standard library and ClaRaCCS may be connected using simple adapters included in the library. In addition, connectors for 
aerosols (unburned coal dust, fly ash) are defined similar to the approach of of Gall et al. [15]. These connectors instantiate the connectors for the flue gas, the coal and the slag. In contrast to Gall's approach, the fly ash is treated as substance of the flue gas so that there is no need for a fourth connector. The Modelica code of e.g. the CoalSlagFlueGas_inlet connector reads

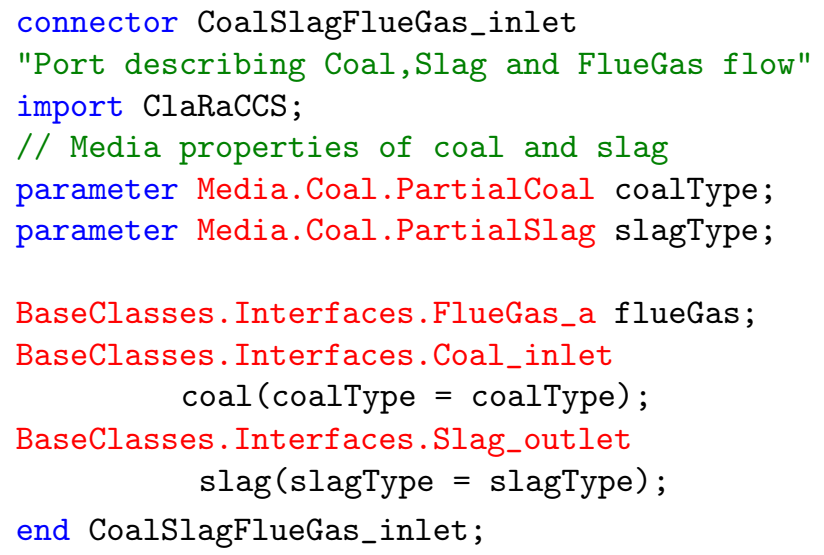

Likewise, a connector for the coal dust and the primary air is available. In addition, components for splitting and joining are provided so that other components in the flue gas path having solely flue gas connectors (as e.g. a deNOx plant) can be connected to a combustion chamber model.

\subsection{Components in the Furnace Package}

\subsubsection{A Simplified Combustion Chamber Model}

Figure 5 shows the tree of the furnace model package. At the top level it provides the model SimpleCombustionChamber which represents a simplified model of detail level 2 (refer to figure 6). It provides physical connectors for the coal dust and primary air, for the slag and flue gas outlet. Based on a stationary stoichiometric combustion calculation, the flue gas composition, the heat $Q_{\text {combustion ob- }}$ tained from combustion and the stoichiometric air ratio $\lambda=\dot{m}_{\text {air }} / \dot{m}_{\text {air }, s t}$ are calculated. The model consists of

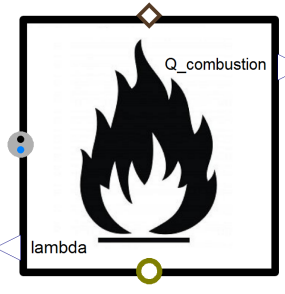

Figure 6: Diagram view of the simplified combustion chamber model. stationary balance equations for the energy, the mass flow, the flue gas components and its composition (i.e. mass balance equations for each single substance considered in the used flue gas mixture). The user can

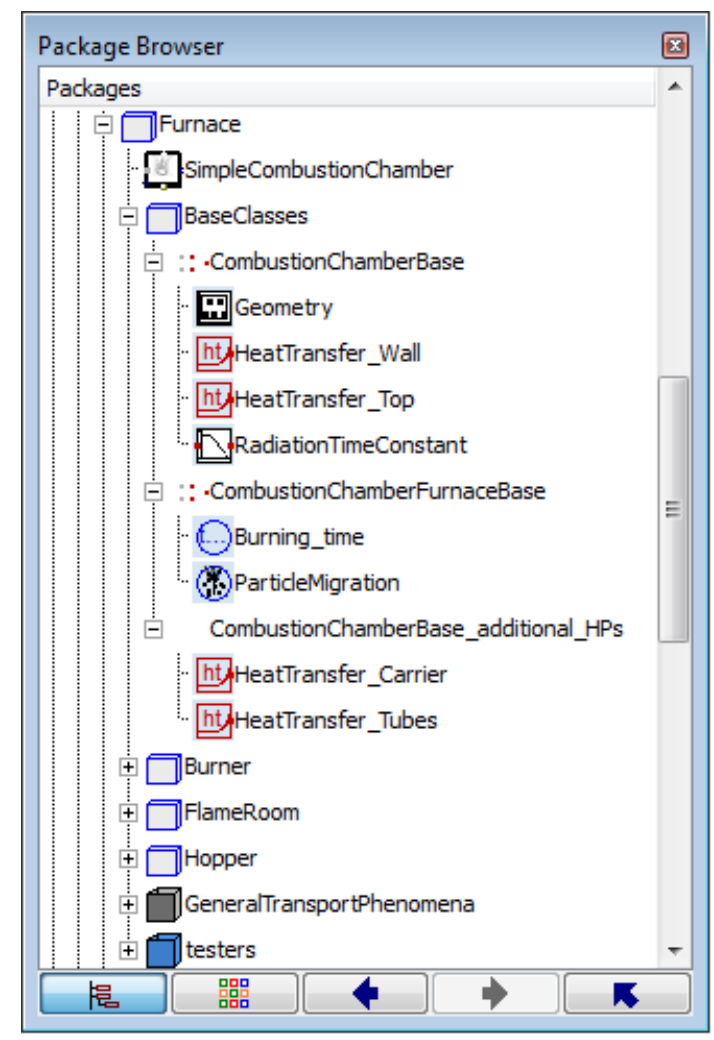

Figure 5: The tree of the furnace model package.

set values for the flue gas outlet temperature, the slag fraction, slag temperature, and the concentration of toxic substances $\left(\mathrm{CO}, \mathrm{NO}_{x}\right.$ and $\left.\mathrm{SO}_{x}\right)$ in the flue gas. Whereas the flue gas and the slag are accessible via physical connectors, $Q_{\text {combustion }}$ and $\lambda$ are provided by real outputs. These important process variables can then be used as inputs to other models, such as a controller for the air ratio. The model has been compared to Ebsilon [12] and has shown good consistency of the results.

\subsubsection{Components for a Detailed Combustion Chamber Model}

Besides the model SimpleCombustionChamber, the furnace package is intended to provide all required components from that a complete -more detailedcombustion chamber model can be built. These components are currently models of detail level 2, i.e. they represent single control volumes for the considered combustion process. Since a complete combustion chamber model will be built from several level of detail 2 models, it yields a spatial discretisation and will thus be a model of detail 3 or 4 .

Figure 7 shows the diagram of a burner model which extends the three base models- namely CombustionChamberBase, 


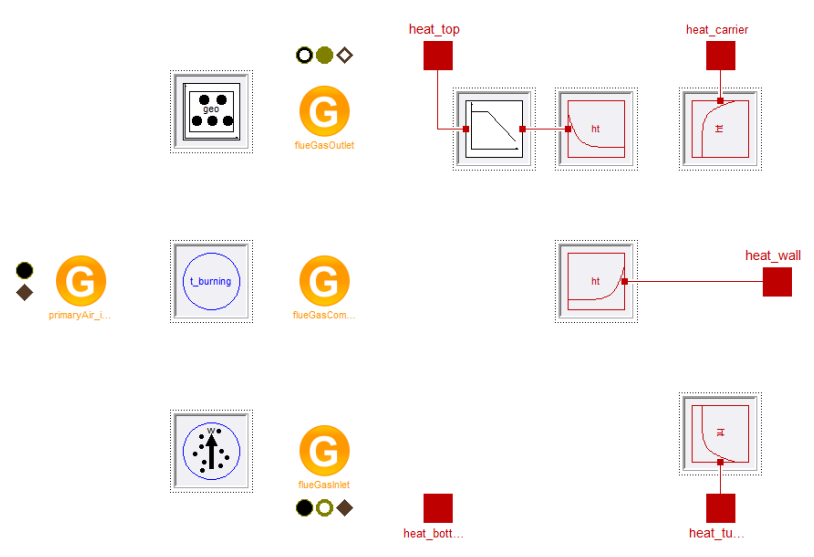

Figure 7: Diagram view of a burner model.

CombustionChamberFurnaceBase and CombustionChamberBase_additional_HPs that are provided by the BaseClasses package (see figure 5).

The partial model CombustionChamberBase provides the definition of the used Media, the instance of the corresponding medium objects and physical connectors. A replaceable model Geometry allows for an adaptation of the combustion chamber's dimensions to the user's needs. Also basic parameters that are common in all furnace components are defined in this base class whereby the duplication of code is avoided ensuring low maintenance effort.

Regarding the physical effects to be considered, besides the connectors for the gas and solid flow, this base model has three connectors for heat flows. They are required to model the heat transfer from the hot flue gas to the combustion chamber wall and the heat transfer between neighboured flame rooms/burners. The heat flows to the top and to the wall are calculated based on the replaceable models HeatTransfer_Top and HeatTransfer_Wall (refer to figure 5p. Please note that the heat flow at the bottom connector is calculated from the heat transfer model HeatTransfer_Top in the respective adjacent burner/flame room. In view of a numerical optimisation, the control volume temperature can be decoupled from that of neighboured ones by using differential states for the temperature at a heat port. Such a state with a certain time constant is provided with the replaceable model RadiationTimeConstant (see figure 5) and is placed in the burner model shown in figure 7 at the top heat connector. Whereas the CombustionChamberBase represents a basic control volume just describing the flow of the gas and solid phase and the heat transfer, the sec- ond partial model CombustionChamberFurnaceBase accounts for the furnace process. It is extended by replaceable models for the burning time and the particle migration time. The third base model CombustionChamberBase_additional_HPs provides two additional heat ports. In this way also the heat flow from the flue gas to e.g. the carrier tubes and the tube bundles of the convective heat exchangers in a boiler model can be modelled. Again, for each heat port replaceable models for the heat transfer correlation are provided.

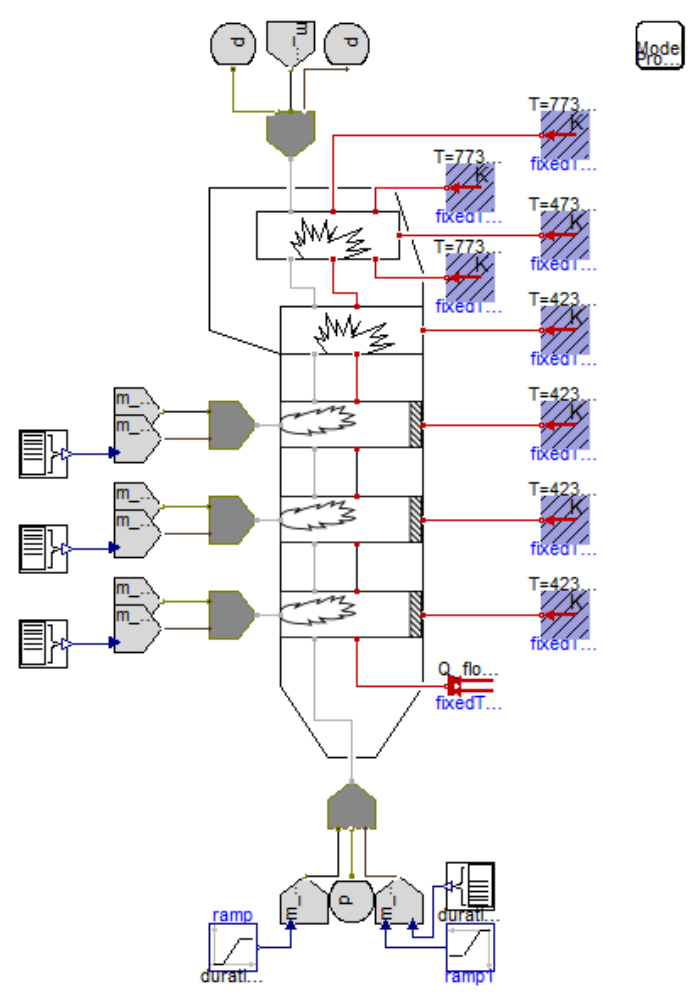

Figure 8: Diagram view of an exemplary combustion chamber model built by the furnace package components described above.

Figure 8 shows the diagram of an exemplary combustion chamber model. In a boiler model the fixed temperature boundaries on the right would be replaced by according water steam tube models.

\section{Example of Use}

The current capabilities of the ClaRaCCS library can be illustrated by a model of an anthracite-fired steam power plant with a coupled post combustion capture unit. For the sake of simplicity and due to current library limitations the complex topology of current Rankine cycles is reduced to the main features. 


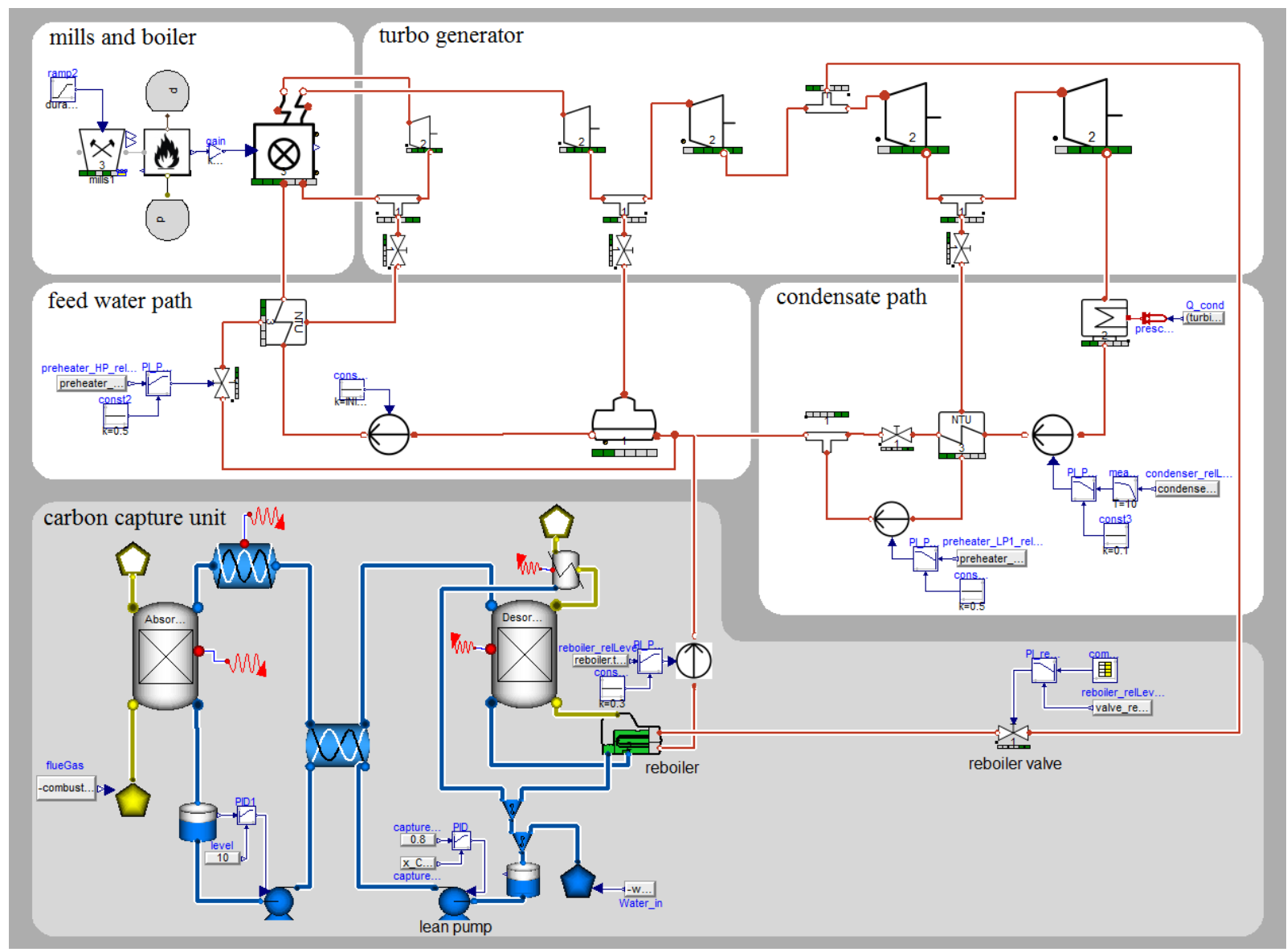

Figure 9: Diagram view of coupled steam plant with carbon capture unit.

\subsection{Example Description}

The model's definition is based on a PCC-retrofit of the existing power plant [13] of Rostock, Germany, see table 1 for its general operation parameters.

Table 1: General overview of power plant of Rostock, Germany

\begin{tabular}{|ll|}
\hline Net output & $509 \mathrm{MW}$ \\
\hline Net efficiency & $43.2 \%$ \\
\hline Live steam pressure & $262 \mathrm{bar}$ \\
\hline Live steam temperature & $545^{\circ} \mathrm{C}$ \\
\hline Live steam mass flow & $417 \mathrm{~kg} / \mathrm{s}$ \\
\hline Re-heat temperature & $562{ }^{\circ} \mathrm{C}$ \\
\hline Re-heat pressure & $54 \mathrm{bar}$ \\
\hline
\end{tabular}

In particular, the model features a set of roller bowl mills, as reported in [16], a reduced combustion chamber and boiler, a turbo-generator with tappings for one high pressure pre-heater, one low pressure pre-heater, the feedwater tank and the reboiler of the PCC. At the low pressure side a condenser, a condensate pump, the pre-heaters, the feedwater tank and the feedwater pump complete the cycle, see figure 9 .
The coupling of furnace outlet and PCC inlet at the flue gas path is currently cut because of missing components for the flue gas cleaning.

The PCC features first-principle models for the absorber and desorber columns and simplified models for pumps and the inner heat exchanger, see [17] for a more detailed description on column modelling.

In order to get a pure feed-forward response of the model, only subordinate controllers are implemented in a simple way. Pumps are used to keep the filling levels of the storage devices within reasonable bounds. The generator power output is controlled by the reboiler valve, which sets the amount of steam that is used to supply heat for the reboiler. Additionally the carbon capture rate is controlled by the lean solvent pump downstream the desorber. Future investigations will have to consider an integrated unit control concept for both the steam cycle and the PCC unit, see [18] for a first approach.

Although the degree of simplification is too high to allow quantitative statements on the transient behaviour, the model is capable to capture the main dynamics in a qualitative manner and shows that the dif- 
ferent aspects of the library work together as desired.

\subsection{Simulation Results}

The extensive steam tapping for the heating of the reboiler introduces the option to provide primary control power by throttling the reboiler valve. Doing so, the low pressure turbine mass flow rate is increased in short term resulting in a significant power step-up. However, a temporary drop of the carbon capture rate has to to be accepted. In figure 10 the power output and the reboiler steam mass flow are displayed indicating that almost full throttling of the valve can lead to a power step of $5 \%$-pts within $30 \mathrm{~s}$. After holding the primary control power for $5 \mathrm{~min}$, the control band is set free within $10 \mathrm{~min}$.

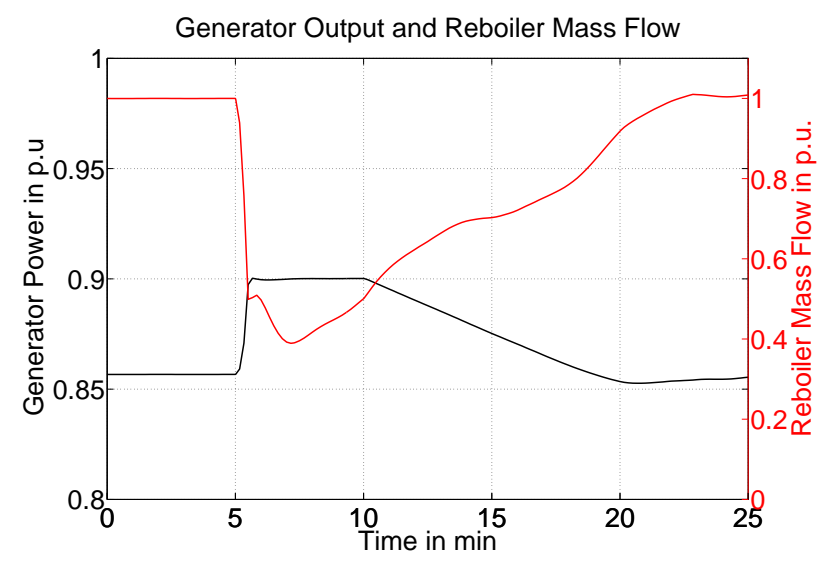

Figure 10: Power output applying reboiler feed reduction.

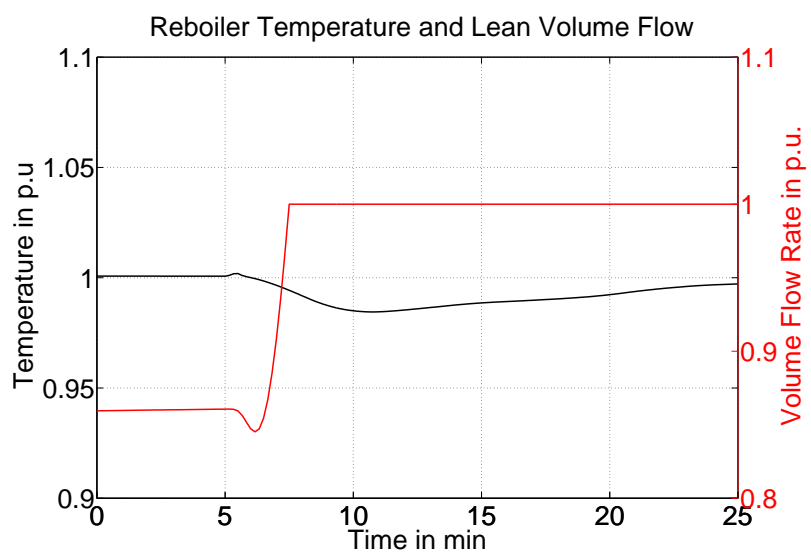

Figure 11: Amine gas treatment characteristic values.

The reboiler temperature in figure 11 shows a moderate drop with a minimum at 10 min of simulation time. Due to the throttling of the valve and the subsequent temperature drop in the reboiler, the lean loading of the solution in the reboiler increases (because less
$\mathrm{CO}_{2}$ is stripped from the solution). This means that a higher flow rate of solution is needed to maintain the targeted capture rate. Hence, the lean pump volume flow increases in order to compensate the higher loading, until the pump reaches its maximum capacity.

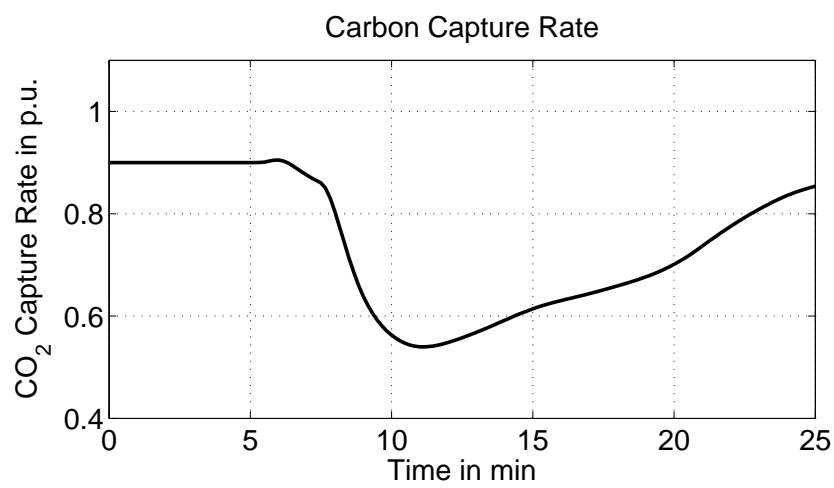

Figure 12: Carbon capture rate during reboiler holdup.

As expected, the additional power output comes at the cost of a strongly reduced carbon capture rate showing its minimum of $55 \%$ at approx. $11 \mathrm{~min}$ simulation time, see figure 12 .

Although the simulation scenario might be strongly simplified and the applied control strategy technically not yet mature, it becomes obvious that the application of highly integrated sub-processes like the amine gastreatment brings up new options for the plant's transient operation mode and economical shifting (tradeoff between revenues from primary control power supply and costs due to $\mathrm{CO}_{2}$ certificates) on the one hand. On the other hand new challenges for the power plant's control system must be tackled.

\section{Summary and Outlook}

In this paper the status of development of the $\mathrm{ClaRaCCS}$ library is presented, which is a central part of the DYNCAP project. In its final stage the library will allow detailed dynamic simulations of power plants coupled to $\mathrm{a} \mathrm{CO}_{2}$ capturing process.

It was demonstrated how the flexible library structure supports the user in order to build up complex power plant models individually tailored to specific simulation goals.

Although in an early state of development, the given simulation example proves that the library is already capable of simulating simplified dynamic operation scenarios for coal fired power plants coupled to a postcombustion $\mathrm{CO}_{2}$ capture process. 
Having almost completed the development of fundamental components for the water steam cycle and the post combustion process, the development will now proceed to the design of subsystems and complete power plant models including a $\mathrm{CO}_{2}$ capturing unit. These models will be validated against measurement data from an existing hard coal power plant and a demonstration post combustion unit.

However, it should be noted that the design of ClaRaCCS allows the easy adaptation of component models in order to feature CCS-retrofits to existing power plants as well as to perform concept studies for planned ones. In this context the development of an integrated control concept is a major challenge. First steps into this direction have already been published in [18]. Moreover the automation of the initialisation process for complex simulations will be a major future direction of work.

Concerning the models for the $\mathrm{CO}_{2}$ capture, the use of external media data shall be supported in the future. In this context it may be necessary to adapt the models in order to maintain performance.

\section{Acknowledgements}

On behalf of the authors we would like to thank all members of the ClaRaCCS team. This research project is supported by the Federal Ministry of Economics and Tech-
Supported by:

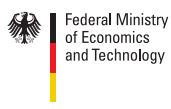

on the basis of a decision
by the German Bundesta nology (project number 03ET2009). For valuable data input and discussions the staff of KNG, EnBW, Vattenfall and E.ON are gratefully acknowledged. We thank the anonymous reviewers for their valuable comments.

\section{References}

[1] B. Metz, O.R. Davidson, P.R. Bosch, and R. Dave. Climate Change 2007: Mitigation. Contribution of Working Group III to the Fourth Assessment Report of the Intergovernmental Panel on Climate Change. IPPC, Cambridge, United Kingdom and New York, NY, USA., 2007.

[2] COORETEC.

http://www $\cdot$ cooretec $\cdot$ de/index $\cdot$ php? index $=$ 21 (retrieved 09 $9^{\text {th }}$ May, 2012).

[3] Dyncap Project, 2011-2014. http://www.kraftwerkforschung.info/en/ mehr-flexibilitaet-fuer-emissionsarmekohlekraftwerke (retrieved $10^{\text {th }}$ May, 2012).

[4] Dymola. Dassault Systèmes, 2012.
[5] Simulation $X^{\circledR}$. ITI Gesellschaft für Ingenieurtechnische Informationsverarbeitung mbH, 2012.

[6] A. Kather, S. Rafailidis, C. Hermsdorf, M. Klostermann, A. Maschmann, K. Mieske, J. Oexmann, I. Pfaff, K. Rohloff, and J. Wilken. Research \& development needs for clean coal deployment. Number CCC/130 in ISBN 978-92-9029-449-3. IEA Clean Coal Centre, January 2008.

[7] J. Oexmann. Post-Combustion $\mathrm{CO}_{2}$ Capture: Energetic Evaluation of Chemical Absorption Processes in Coal-Fired Steam Power Plants. PhD thesis, University Hamburg-Harburg, Institute of Energy Systems, Hamburg, January 2011. ISBN 978-3-86955-633-8.

[8] G. T. Rochelle. Amine Scrubbing for $\mathrm{CO}_{2}$ Capture. Science, 325:1652-1654, 2009.

[9] A. Kather and G. Scheffknecht. The oxycoal process with cryogenic oxygen supply. Naturwissenschaften, 96(9):993 - 1010, 2009.

[10] M. Bonvini and A. Leva. Scalable-detail modular models for simulation studies on energy efficiency. In Proceedings 8th Modelica Conference, Dresden, Germany, March 20-22, 2011, 2011.

[11] AspenPlus ${ }^{\circledR}$. Aspen Technology, Inc., 2011.

[12] EBSILON ${ }^{\circledR}$ Professional. Evonik Energy Services $\mathrm{GmbH}, 2011$.

[13] KNG Power Plant Rostock.

http://www.kraftwerk-rostock.de (retrieved 09 ${ }^{\text {th }}$ May, 2012).

[14] EnBW Energy. 2010 Innovation Report, 2010.

[15] L. Gall, K. Link, and H. Steuer. Modeling of gasparticle-flow and heat radiation in steam power plants. Modelica Conference, Dresden, Germany, March 20$22,2011$.

[16] P. Niemczyk, P. Andersen, J.D. Bendtsen, T.S. Pedersen, and A.P. Ravn. Derivation and validation of a coal mill model for control. In IFAC Symposium on Power Plants and Power Systems Control 2009, Tampere, July 2009.

[17] K. Dietl, A. Joos, and G. Schmitz. Dynamic analysis of the absorption/desorption loop of a carbon capture plant using an object-oriented approach. Chemical Engineering and Processing: Process Intensification, 52:132 - 139, 2011.

[18] F. Gottelt, K. Wellner, V. Roeder, J. Brunnemann, G. Schmitz, and A. Kather. A Unified Control Scheme for Coal-Fired Power Plants with Integrated Post Combustion $\mathrm{CO}_{2}$ Capture. In 8th IFAC Conference on Power Plant \& Power System Control, Toulouse, 2012. accepted for publication. 